\title{
Influences of protein to energy ratios in breakfast on mood, alertness and attention in the healthy undergraduate students
}

\author{
Yao-Chi Zeng ${ }^{1^{*}}$, Shun-Min $\mathrm{Li}^{1}$, Guo-Liang Xiong ${ }^{1}$, Hui-Min $\mathrm{Su}^{2}$, Jian-Cheng $\mathrm{Wan}^{3}$ \\ ${ }^{1}$ Shenzhen Traditional Chinese Medicine Hospital, Shenzhen, China; ${ }^{*}$ Corresponding Author: 0731zyc@163.com \\ ${ }^{2}$ Shenzhen Bao'an Maternal and Child Health Hospital, Shenzhen, China; \\ ${ }^{3}$ Guangzhou University of Traditional Chinese Medicine, Guangzhou, China.
}

Received 12 February 2011; revised 17 March 2011; accepted 6 May 2011.

\begin{abstract}
Background: The high protein (HP) breakfast reduced gastric emptying and the most satiating macronutrient appears to be dietary protein. Few studies have investigated the effects of protein to energy ratio in breakfast on mood, alertness and attention. Objective: This study was designed to investigate whether the HP breakfast is more beneficial to mood, alertness and attention of the healthy undergraduate student than adequate-protein (AP) breakfast through the rising body temperature and remaining stable blood glucose or through other physiologic processes. Methods: Thirteen healthy male undergraduate students (18 - 23 y) were studied in a double-blind, randomized crossover design. Blood samples, body temperature, satiety, mood and Continuous Performance Test (CPT) were assessed after the consumption of two isocaloric breakfasts that differed in their protein and carbohydrate content: an HP breakfast $(50 \%, 30 \%$, and $20 \%$ of energy from protein, carbohydrate, and fat, respectively) or an AP breakfast $(10 \%, 70 \%$, and $20 \%$ of energy from protein, carbohydrate, and fat, respectively). Results: Consumption of an HP breakfast resulted in more steady glucose and insulin than AP breakfast consumption $(p<$ $0.05)$. Satiety scores and body temperature were higher after HP breakfast consumption $(p<0.05)$. And most important, the positive mood and CPT scores were higher after HP breakfast than after AP breakfast intake $(p<0.05)$. Conclusion: HP breakfast can effectively stabilize postprandial serum glucose concentration and elevate postprandial temperature of healthy male undergraduate students. Our present findings dem-
\end{abstract}

onstrate the relationship between HP breakfast and mood, alertness and attention. This study indicated that HP breakfast may enhance human performance probably by increasing the thermic effect of a food and elevating body temperature.

Keywords: Protein; Body Temperature; Mood; Alertness; Attention

\section{INTRODUCTION}

It is widely believed that there exists a strong relationship between eating and mood, and that diet and particular dietary constituents can have important influences on behaviour, including alertness and mental performance[1-3]. Wurtman RJ and Wurtman JJ [1] developed the hypothesis that carbohydrates can relieve depression because that carbohydrate intake enhanced serotonin synthesis. Their major theory was that a meal high in carbohydrate increased the rate that tryptophan entered the brain, leading to an increase in the level of the neurotransmitter serotonin that modulates mood. As for fat, it is thought that in many countries current population intakes of the n-3 long-chain PUFA (LCPUFA; also known as long chain omega-3 fatty acids) EPA and DHA are lower than optimal for a variety of health outcomes [2,4]. However, Peter J. Rogers' [5] studies that have shown substantially increasing EPA and DHA intake for 3 months was found not to have beneficial or harmful effects on mood in mild to moderate depression. With respect to energy expenditure, it is known that protein has the highest and most prolonged thermic effect of the separate macronutrients $(20-30 \%)$, followed by carbohydrate $(5-15 \%)$ and fat $(0-3 \%)$ [3]. Protein has been observed to increase satiety to a greater extent than carbohydrate and fat and therefore can reduce energy intake $[6,7]$. Now many positive outcomes associated with increased dietary protein are thought to be due pri- 
marily to lower energy intake associated with increased satiety [8-11], reduced energy efficiency and/or increased thermogenesis $[5,12,13]$, positive effects on body composition, specifically lean muscle mass[14-16], and enhanced glycemic control [16,17]. In addition, several studies showed that eating breakfast can improve cognitive performance and attention-concentration compared with omitting breakfast [18-20], but the effect of each macronutrient was not defined because of various methodologic issues. In fact, the study [21] about the relationship of macronutrients and memory performance indicated all of the macronutrients improved paragraph recall $15 \mathrm{~min}$ after ingestion, suggesting that energy intake can enhance specific aspects of cognition, in addition to the effects of energy ingestion on memory, each macronutrient enhanced performance on various tasks, possibly via unique mechanisms. Indeed, all three kinds of macronutrients led to an initial, robust improvement on delayed paragraph recall. Each macronutrient may exert different effects on cognition by additional, unique mechanisms [21]. Human beings should not ingest pure protein, carbohydrate, or fat, but should pay attention to the content of the various macronutrients reasonably matched. However, there is little support for the influences of protein to energy ratio in breakfast on mood, alertness and attention in healthy human volunteers. The aim of the present study was to examine the effects of HP breakfast on mood, alertness and attention of undergraduate student. It was hypothesised that (1) some detrimental mood would be alleviated by HP breakfast; and (2) postprandial alertness and attention be enhanced by HP breakfast.

\section{SUBJECTS AND METHODS}

\subsection{Subjects}

Thirteen healthy male volunteer subjects, mean age 21.5 (S.D. 2.8), were recruited from a cohort of present university students. The study was approved by the ethical committee of the Guangzhou University of Traditional Chinese Medicine. All subjects gave their informed consent, both verbally and in writing, after being informed about the study. All subjects filled out a questionnaire on lifestyle, medical history, and dietary habits. They were nonsmokers, no color blind, and had a moderate body mass index (BMI) of 21.3 (S.D. 1.1) $\mathrm{kg} / \mathrm{m}^{2}$. Exclusion criteria for participation were chronic and current illness; a history of psychiatric or medical illness; medication use; metabolic, hormonal, or intestinal diseases; irregular diets or deviant eating habits; excessive use of alcohol, cigarettes, coffee, or drugs; allergy to milk products; All subjects who participated in the experiment had a BMI in the normal range of Asian adults
(BMI: $18.5 \mathrm{~kg} / \mathrm{m}^{2}-22.9 \mathrm{~kg} / \mathrm{m}^{2}$ ), were nonsmokers, and were not allowed to drink alcohol or take any drug for 2 $\mathrm{d}$ before and during the experiment.

\subsection{Study Design}

A repeated-measures, counterbalanced cross-over design was used. Each subject was tested in two sessions separated by exactly 1 week. Subjects were told that various physiological and psychological effects of food intake were examined, but they were not aware of ingesting different ratios of macronutrients. To avoid interferences of learning with treatment effects, the subjects had to practice all questionnaires and tests on two separate days in the week before the experimental period. In this way, the subjects were familiar with the experimental procedure.

To ensure similar baseline conditions, subjects were not allowed to ingest alcohol or caffeine-containing drinks and foods, and were requested to refrain from violent physical activity the day before each testing. In addition, all subjects consumed an identical supper meal between 1800 and $1900 \mathrm{~h}$ on the evening before each testing. The meal consisted of steamed rice (raw rice 150 $\mathrm{g})$, steamed fish (100 g), almond beancurd (80 g), vegetables and fruits $(250 \mathrm{~g})$. It provided approximately 3400 $\mathrm{kJ}$, with $65 \%, 15 \%$ and $25 \%$ of the energy derived from carbohydrates, protein and fat, respectively, and the composition of the meal suggested a medium glycemic index (GI). In order to avoid a depletion of liver glycogen stores over night the supper was rich in carbohydrates and scheduled late. Subjects were asked to ingest all supper and to have no further food or drinks except water before testing. Subjects were also asked to sleep for at least $8 \mathrm{~h}$. Subjects arrived at the institute by public transport. All subjects were tested simultaneously, beginning at 0700 . Just after arrival, subjects had to fill out a questionnaire checking their compliance with the restrictions on the day before as well as their sleep quality and their actual mental and subjective physical performance. Before the test meal, baseline assessments were taken in the order (1) questionnaire, (2) alertness and attention, (3) mood, (4) satiety, (5) body temperature, (6) blood samplings. Twenty minutes were scheduled for each of these assessments. Subsequently, the cream-like test meal was served in a dessert bowl. Subjects spent 10 min to eat whole meal with a spoon and afterwards 5 min to fill in a questionnaire concerning the meal's acceptance and sensory properties. For repeated postprandial measurements within the next $4 \mathrm{~h}$, subjects rotated each hour through the same stations as at baseline. Subjects had free access to pure water during the whole study, but no additional food or beverages intake was permitted. Preparation and intake of test breakfast were 
controlled by a dietitian. Subjects were sedentary, and only reading was allowed in a study room. (Figure 1)

\subsection{Test Breakfast}

The two breakfasts consisted of isoenergetic $(3400 \mathrm{~kJ})$, differed in content of the carbohydrates and protein. Suspensions mixed at three different ratios: the HP meal with a $\mathrm{PRO} / \mathrm{CHO} / \mathrm{FAT}$ ratio of 5:3:2; the AP breakfast with a PRO/CHO/FAT ratio of 1:7:2. All test meals was controlled by a dietitian and had similar volume and sensory properties (taste, consistency and color). They were freshly prepared by mixing appropriate quantities of basic ingredients and water to obtain $500 \mathrm{ml}$. Different kinds of protein (milk protein and egg white powder) and carbohydrates (glucose, maltodextrin, rice starch) were combined to cover a broad range of the representative compounds that might affect cognitive behavior differentially. The carbohydrate proportion of the test meals suggested a medium GI. A differentiation was only made in the content of carbohydrates and protein, respectively (Table 1). The meals were served in a random order one week apart. Each meal was ingested within 10 minutes. The energy content of the test meals was in the range of the subjects' habitual energy intake in the morning. Acceptance and sensory homogeneity of the two meals were tested by staff members of clinical nutrition department.

\subsection{Study Protocol}

The study was a 2-day, randomised, crossover trial. At day 01 , subjects were randomly assigned to receive a breakfast with a high or low ratio of simple-to-complex carbohydrates. At day 08, after at least 1-week wash-out period, subjects received the alternate breakfast. The subjects were instructed to eat and drink the same foods the evening before a test day. After they subjects arrived at the institute, they filled out a wellbeing questionnaire, and were weighed. Their subjects blood glucose and insulin concentrations were examined after an 8 hour fast. When the subjects rested $10 \mathrm{~min}$, their body temperature were measured. Then, the subjects started eating the test breakfast immediately. After breakfast, which was consumed in $10 \mathrm{~min}$, the subjects were not allowed to eat or drink anything during $4 \mathrm{~h}$. Blood was collected at $0,60,120,180,240 \mathrm{~min}$ after breakfast. Immediately after each blood sample was taken, the subjects filled out Visual Analogue Scales (VAS) to measure their subjective feelings of hunger, fullness. Simultaneously, body temperature was recorded .The subjects received tests about mood, alertness and attention at fasting, 120, 240 min after breakfast.

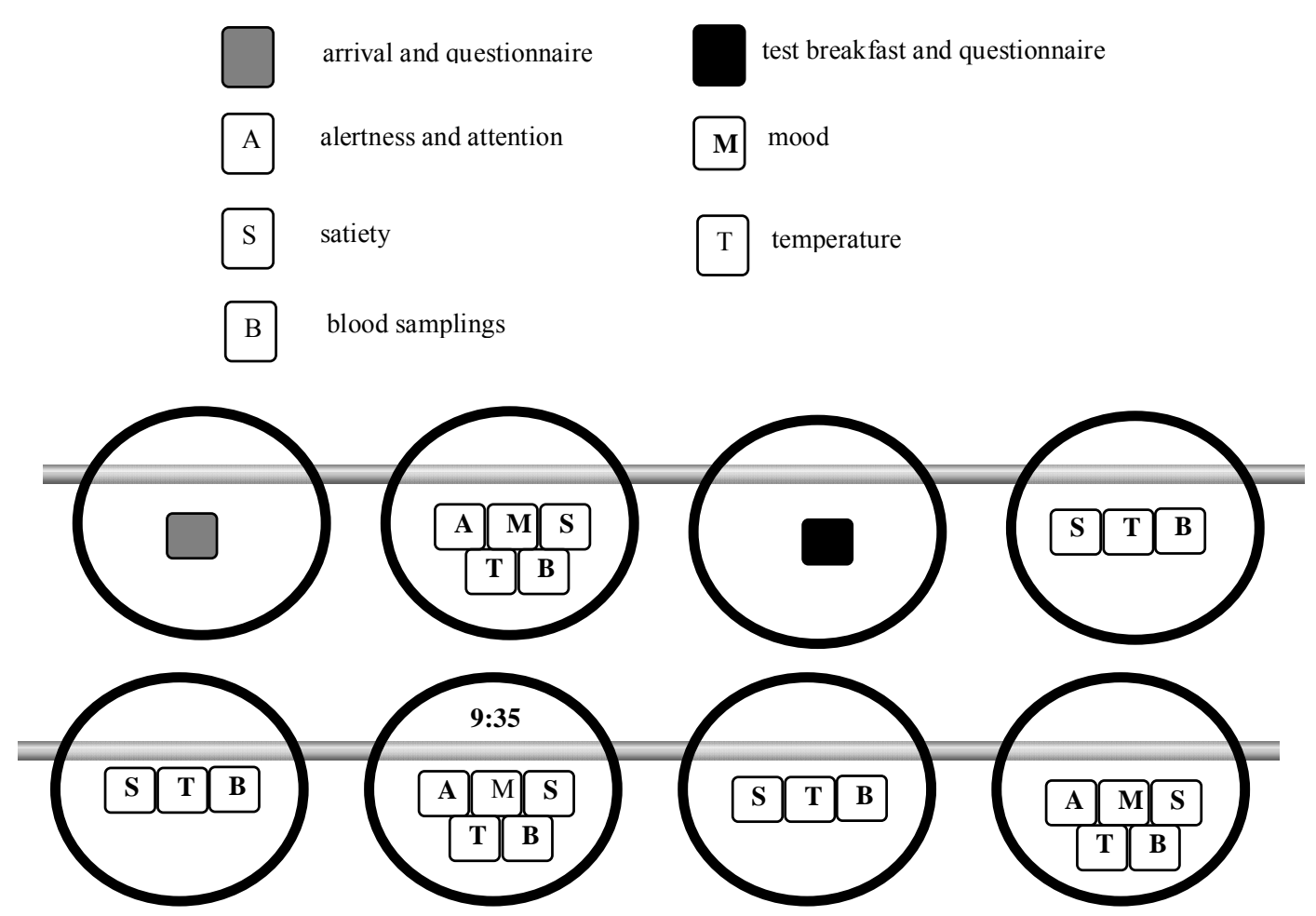

Figure 1. Schedule of experimental procedures for the subjects on each test morning. The first and second period followed the same order of procedures. 
Table 1. Composition of the cream-like test meals $(3400 \mathrm{~kJ} ; 50 \mathrm{ml})$.

\begin{tabular}{lcc}
\hline \multicolumn{1}{c}{$\begin{array}{c}\text { Basic ingredients } \\
(\mathrm{g})^{\mathrm{a}}\end{array}$} & $\begin{array}{c}\text { Highprotein } \\
\text { PRO/CHO/FAT [5:3:2] }\end{array}$ & $\begin{array}{c}\text { adequate-protein } \\
\text { PRO/CHO/FAT [1:7:2] }\end{array}$ \\
\hline Glucose $^{\mathrm{b}}$ & 6.1 & 14.9 \\
Maltodextrin $^{\mathrm{c}}$ & 52 & 119.7 \\
Rice starch $^{\mathrm{d}}$ & 6.1 & 14.9 \\
Milk protein $^{\mathrm{e}}$ & 95.4 & 18.9 \\
Dried chicken $_{\text {Egg white }}$ & 10.6 & 2.1 \\
powder $^{\mathrm{f}}$ & & \\
Soybean oil & & \\
Water & 15 & 15 \\
\hline
\end{tabular}

${ }^{\mathrm{a}}$ For sensory acceptance, $0.5 \mathrm{~g} / \mathrm{L}$ of a nonenergetic powdered mixture of sweeteners (aspartame:acesulfame- $\mathrm{K}=1: 1$ ) as well as 3 $\mathrm{ml} / \mathrm{L}$ of vanilla flavor (Beijing first delicious Food Co., LtdSwitzerland) were also added before mixing. The creams were later colored, using an egg-yellow food color $(1 \mathrm{ml} / \mathrm{L}$, Shanghai Dyestuffs Research Institute Co., Ltd. China), to get an identical appetizing yellow color. ${ }^{b}$ Glucose, commercially available from Tanye (Tianjin) Food Co., Ltd. China. ${ }^{\mathrm{c}}$ Maltodextrin (Tanye). ${ }^{\mathrm{d}}$ Rice strarch (Tanye). ${ }^{\mathrm{e}}$ Milk protein, commercially available from Shanghai Insight Protein Nutrition Institute, China. ${ }^{\mathrm{f}}$ egg white powder, commercially available from Shanghai Insight Protein Nutrition Institute, China. ${ }^{g}$ Soybean oil, commercially available from COFCO, China.

\subsection{Blood Glucose and Insulin}

Blood was collected by finger prick with a DR- II Automatic Blood Sampler lancet device (Eicom, Japan). Plasma glucose was measured by using a blood glucose meter (OneTouch Ultra, LifeScan Inc.). Serum was pooled for each subject, and plasma insulin was measured by radioimmunoassay using commercial kits (Beijing North Institute of Biological Technology, China).

\subsection{Body Temperature Measurement}

Subjects were instructed to remain awake and not to move, fidget or talk once test breakfast was finished eating. Body temperature was measured by means of a rectal thermistor (Zhangzhou Shuangjia Medical Equipment Co., Ltd, China), except during showers and bowel movements, and room temperature was maintained at 24 $-25^{\circ} \mathrm{C}$ as measured with an air conditioner.

\subsection{Satiety}

A validated satiety score numerical scale was used according to the method of Haber et al [23] on the basis of a scoring system with grades from $-10 \mathrm{~cm}$ (extreme hunger) to $10 \mathrm{~cm}$ (extreme satiety) VAS. VAS are often used to measure subjective appetite sensations and the validity and reproducibility have been shown in several studies [23,24]. Subjects were instructed to rate themselves by marking the scale at the point that was most appropriate to their feeling at that time. The distance from this point to the left end of the scale was measured in $\mathrm{mm}$; changes from baseline were calculated by subtracting the baseline score $(-5 \mathrm{~min})$ from the score at a certain time point.

\subsection{Mood and Alertness State}

The VGZ [25] is a self-administered questionnaire assessing how participants "feel at the moment." Subjects were asked to rate 15 items in relation to their mood. The items were clustered into the 5 dimensions of negative affect (depressed, unhappy, and queasy), positive affect (happy, well, and cheerful), information uptake (fascinated, interested, and uninterested), arousal (calm, nervous and agitated), and alertness (tired, sleepy and awake). All answers were given on a 5-point rating scale ranging from not at all to very much.

\subsection{Continuous Performance Test}

The continuous performance test (or continuous attention test) presents stimuli-target and non-target in a mixture at regular intervals. The CPT is a tool to test task vigilance and distractibility by allowing the subject to react in the presence of a prescribed specific target. Visual stimuli consisted of individual letters and were presented sequentially on a computer screen for $250 \mathrm{~ms}$ each. Subjects were instructed to press a button whenever the letter A (correct cue) was followed by the letter $\mathrm{X}$ (correct target). All other sequences were to be ignored, including sequences in which an incorrect cue (designated ' $\mathrm{B}$ ', but comprising all letters other than $\mathrm{A}$ or $\mathrm{X}$ ) was followed by the target letter $(\mathrm{X})$ or sequences in which a correct cue (A) was followed by an incorrect target (designated ' $\mathrm{Y}$ ', but comprising all letters other than A or X). Stimuli were presented in four blocks of 280 stimuli (140 pairs) each. Within each block, 50\% of 
the cue-target sequences were presented with short $(0.8 \mathrm{~s})$ interstimulus interval (ISI) and 50\% with long ISI (4 s). Short and long ISIs were pseudorandomly intermixed. The time between stimulus pairs was constant at $0.8 \mathrm{~s}$. Of the stimulus pairs, 70\% were AX sequences; all other sequences (BX, AY, BY) occurred with a probability of 0.1 each. The results were converted into values of assessments on the basis of standard computation from the normal group of the same age [26]. The measured values were used for statistical analyses.

\subsection{Statistics}

All statistical analyses were performed with SPSS version 15.0 for Windows (SPSS Inc., Chicago, IL, USA). Results were expressed as mean \pm standard deviation (s.d.), unless stated otherwise. The obtained data (blood parameters and questionnaires) were analysed by means of t-tests to investigate the differences between the two sorts of breakfast. A repeated-measures analysis of variance was carried out to determine possible differences between conditions. Linear correlation analyses were performed to determine the relations between body temperature and selected variables. Effects of HP were evaluated using repeated-measures ANOVAs with sessions (HP vs AP) and time (baseline vs HP/AP administration) as repeated measures. For the analyses of performance of CPT, dependent measures consisted of hit rate (correct detection of $\mathrm{AX}$ sequences) and false alarm rates to $\mathrm{BX}, \mathrm{AY}$, or $\mathrm{BY}$ sequences. Effects of $\mathrm{HP}$ breakfast on hit rate were evaluated with $2 \times 3 \times 2$ factorial repeated-measures ANOVAs with session (HP vs AP), time (baseline vs HP/AP administration), and ISI (short vs long) as repeated measures. For analyses of false alarm rates, an additional within-subject factor with three levels denoting false alarm type (BX vs AY vs BY) was included. Differences between rates of $\mathrm{BX}$ errors and AY and BY errors, respectively, during the two phases of both sessions were evaluated with simple within-subject contrasts involving session (contrast: HP vs AP), time (contrast: Baseline vs HP/AP administration), and false alarm type (contrast: BX vs AY; BX vs $B Y)$. Post hoc paired $t$-tests were used to assess specific differences if indicated. Significance was defined as $P<$ 0.05 .

\section{RESULTS}

\subsection{Glucose and Insulin}

Postprandial plasma glucose and insulin concentrations after the HP were increased less than after the AP within 60 minutes. However, plasma glucose and insulin concentrations after the HP meal were decreased less than after the AP 60 minutes, with significant differences between the HP and AP, with significant differences between the HP and AP meals. There were also significant Meal $\times$ Time interactions $(F=1745.32, P=0.000$ for glucose; $F=886.80, P=0.000$ for insulin) (Figure 2).

\subsection{Body Temperature}

Body temperature rose steadily all experiment session on both diets. The change in body temperature from the fasting baseline value was $+0.1{ }^{\circ} \mathrm{C},+0.1^{\circ} \mathrm{C},+0.2^{\circ} \mathrm{C},+0.4$ ${ }^{\circ} \mathrm{C}$ at $0 \mathrm{~min}, 60 \mathrm{mim}, 120 \mathrm{~min}, 180 \mathrm{~min}$ and $240 \mathrm{~min}$ after the AP breakfast meal respectively; after the HP breakfast meal, the change in body temperature from the
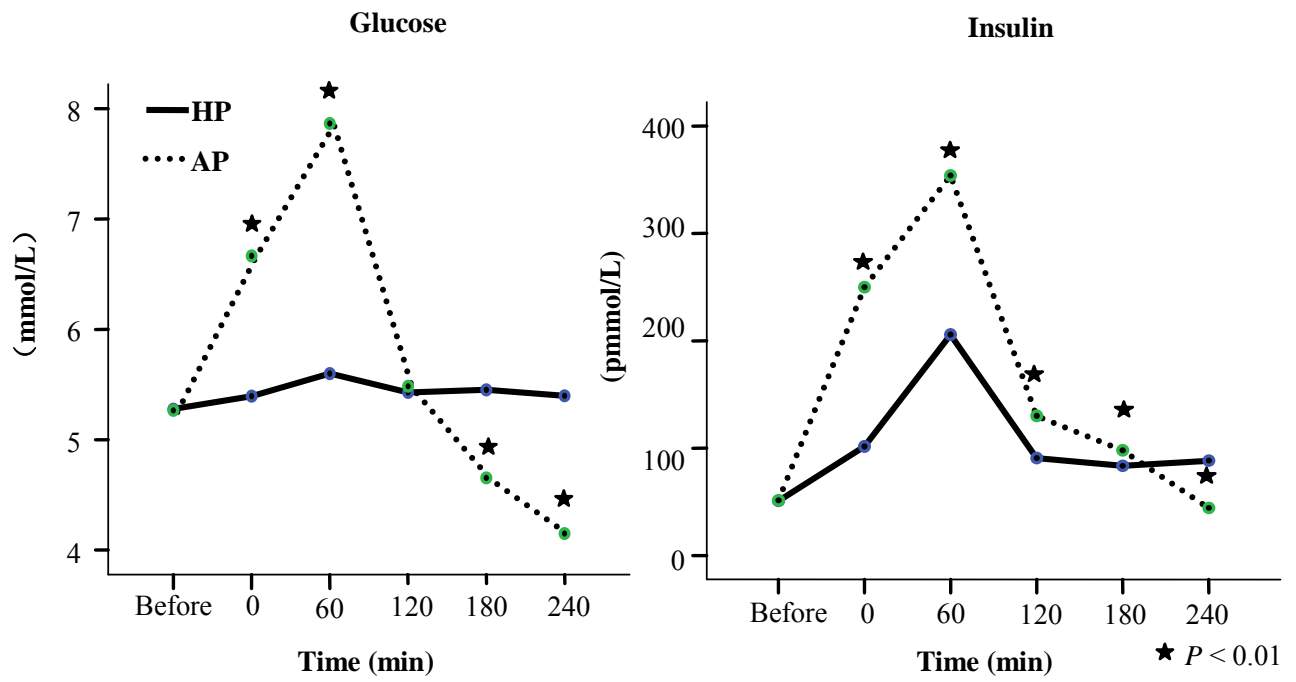

Figure 2. Profile plots for glucose and insulin responses to HP breakfast and AP breakfast. Mean (S.E.M.); $\mathrm{n}=13$. 
fasting baseline value was $+0.1^{\circ} \mathrm{C},+0.2^{\circ} \mathrm{C},+0.6^{\circ} \mathrm{C},+0.8$ ${ }^{\circ} \mathrm{C},+0.7^{\circ} \mathrm{C}$ respectively. Body temperature after HP increased more than AP $\left(t_{120 \text { min }}=2.41, p=0.024 ; t_{180 \text { min }}=\right.$ $\left.3.77, p=0.001 ; t_{240 \min }=3.88, p=0.001\right)$ There were also significant Meal $\times$ Time interactions $(F=74.56, P=$ 0.000) (Figure 3).

\subsection{Satiety}

Ingestion of HP breakfast resulted in a significantly higher satiety than the AP breakfast, with significant differences between the HP and AP meals. There were also significant Meal $\times$ Time interactions $(F=106.03, P$ $=0.000)$ (Figure 4).

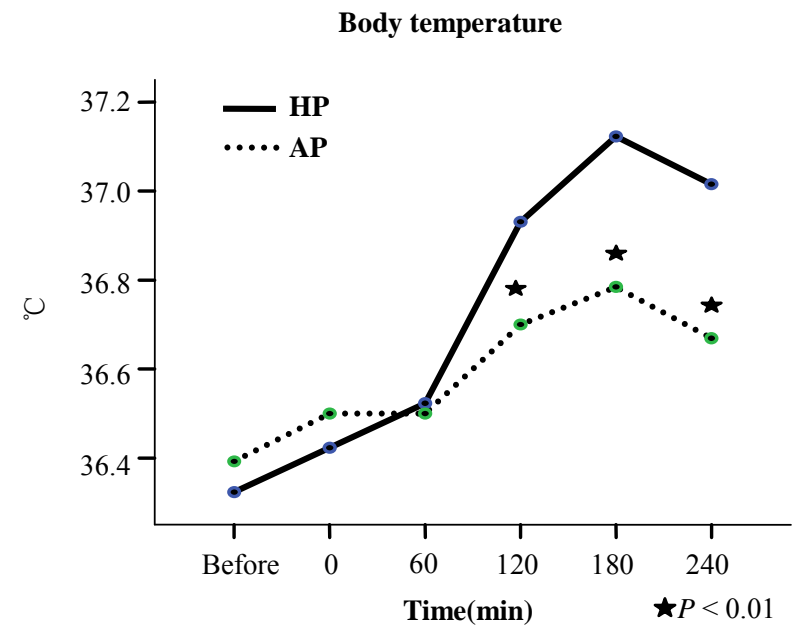

Figure 3. Profile plots for body temperature responses to HP breakfast and AP breakfast. Mean (S.E.M.); $n=13$.

\subsection{Mood and Alertness State}

Consumption of breakfast showed positive effects on the mood of the study population. Intake of HP breakfast caused improvements in positive affect (time $240: t=5.22$, $P=0.000$ ), information uptake (time $120: t=2.89, P=$ 0.008 ; time $240: t=2.67, P=0.013$ ) and alertness (time $_{120}: t=2.77, P=0.011 ;$ time $_{240}: t=3.07, P=0.005$ ) and a decrease in negative affect $\left(\right.$ time $_{120}: t=-2.36, P=$ 0.027 ; time $\left._{240}: t=-2.91, P=0.008\right)$ and arousal (time $_{120}: t=-2.37, P=0.026$; time $240: t=-2.44, P=$ $0.023)$. There were also significant Breakfast $\times$ Time interactions (Table 2).

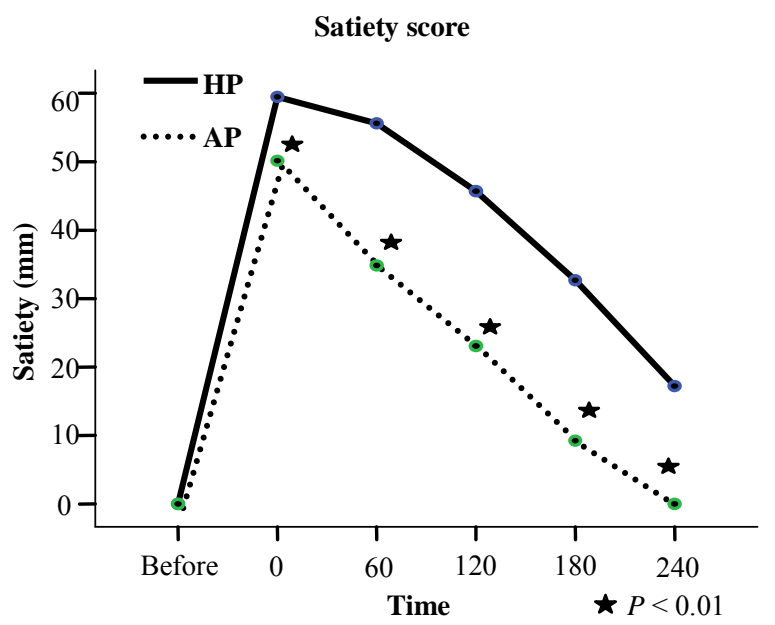

Figure 4. Profile plots for satiety score responses to HP breakfast and AP breakfast. Mean (S.E.M.); $n=13$.

Table 2. Effect of breakfast on mood (VGZ) and results of multifactorial analysis of variance with repeated measures.

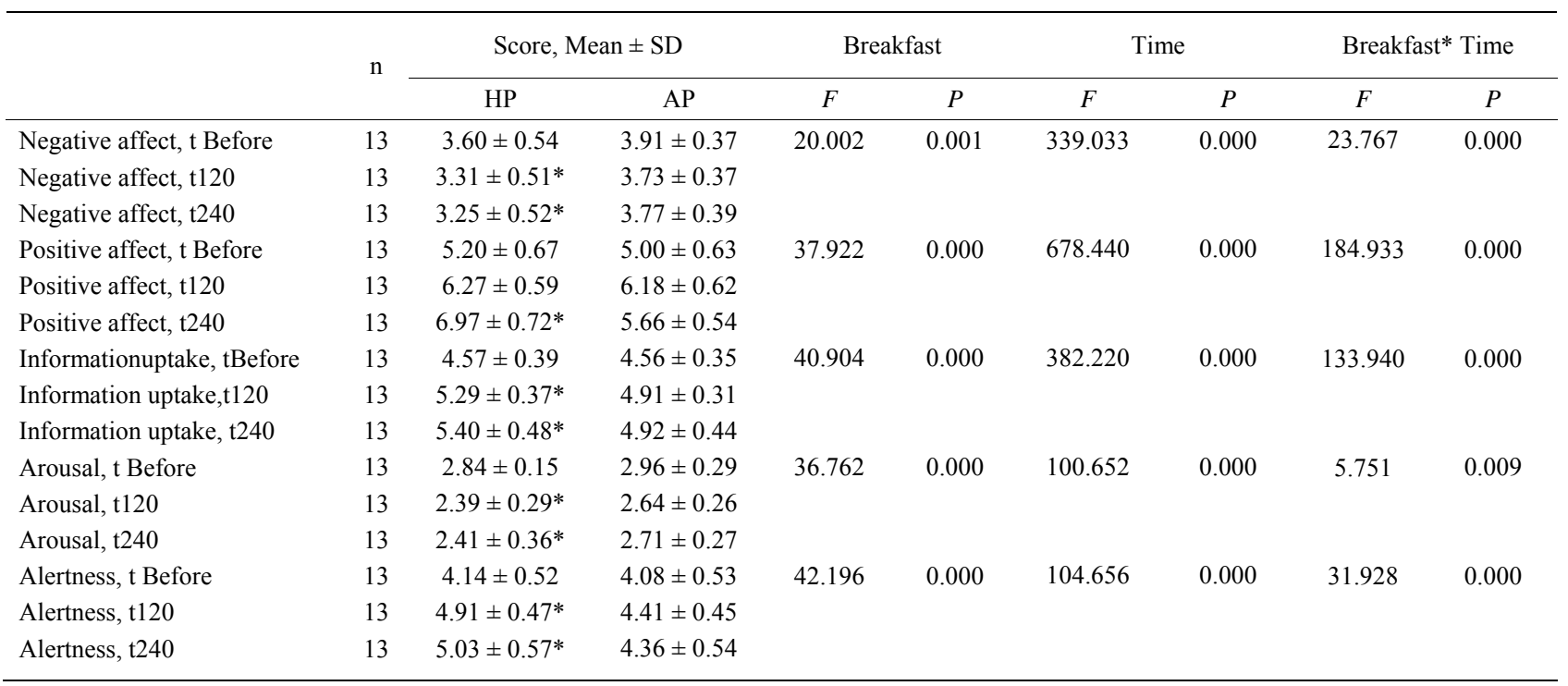

*Significantly different from AP, $P<0.05$ (mixed-model ANOVA). 


\subsection{Continuous Performance Task}

HP breakfast was associated with a significant raise the hit rate at both ISIs. Post hoc $t$-tests confirmed significantly higher hit rates during HP breakfast than during the baseline and AP session. HP breakfast was associated with a decline of false alarms, which was most pronounced for false alarms to AY and BX sequences at long ISIs. HP breakfast also declined for false alarms to $\mathrm{AY}$ and BX sequences at short ISIs. In addition, there were not false alarms to BY at any moments in two sessions (Figure 5).

\section{CORRELATIONS}

\subsection{Blood Glucose and Target Variables}

Three kinds of positive emotion were correlated with concentrations of blood glucose at $240 \mathrm{~min}\left(r_{240 \mathrm{~min}}=\right.$ $0.65, p=0.000)$. Two kinds of negative emotion were negative correlation with concentrations of blood glucose $\left(r_{240 \min }=-0.53, p=0.006\right)$. Total continuous performance task scores at $240 \mathrm{~min}$ were correlated with concentrations of blood glucose $\left(r_{240 \mathrm{~min}}=0.87, p=\right.$ $0.000)$. No significant associations were observed between total CPT scores and concentrations of blood glucose at $0 \mathrm{~min}, 120 \mathrm{~min}$.

\subsection{Body Temperature and Target Variables}

Three kinds of positive emotion at three moments were correlated with body temperature significantly $\left(r_{\text {be- }}\right.$ fore $=0.86, p=0.000 ; r_{120 \min }=0.95, p=0.000 ; r_{240 \mathrm{~min}}=$ $0.95, p=0.000)$. Two kinds of negative emotion at three moments were negative correlation with body tempera- ture $\left(r_{\text {before }}=-0.78, p=0.000 ; r_{120 \text { min }}=-0.95, p=0.000\right.$; $\left.r_{240 \text { min }}=-0.91, p=0.000\right)$. Furthermore, total continuous performance task scores before breakfast, at $120 \mathrm{~min}$ and $240 \mathrm{~min}$ after breakfast all were correlated with body temperature $\left(r_{\text {before }}=0.59, p=0.002 ; r_{120 \text { min }}=0.73\right.$, $\left.p=0.000 ; r_{240 \min }=0.85, p=0.000\right)$.

\section{DISCUSSION}

The present study showed that differences within protein to energy ratios in an isoenergetic breakfast can result in a different effect on perception of satiety, mood state and CPT scores in healthy male subjects. Our data reveal significant HP breakfast meal effects as well as Meal $\times$ Time interactions for CPT scores after the ingestion of meals with different protein to energy ratios in the morning. Overall CPT performance was better after HP breakfast meal than after AP breakfast. In addition, changes in CPT performance and mood were related to postprandial changes in glucose concentrations and body temperature. Two test meals were moderately liked by the subjects. As energy content, volume, acceptance, and sensory properties of our test meals were matched, the observed effects on metabolic, mood, and CPT scores can be attributed to the ratio of protein to energy ingested. Interpreting cognitive effects after macronutrient ingestion, the energy content, sex, age and the constitution of the subjects as well as the time have to be considered [27]. Our subjects were healthy young male students, and the test meals matched their habitual breakfast size. The subjects' glycogen stores were approximately not completely depleted because of the carbohydrate-rich
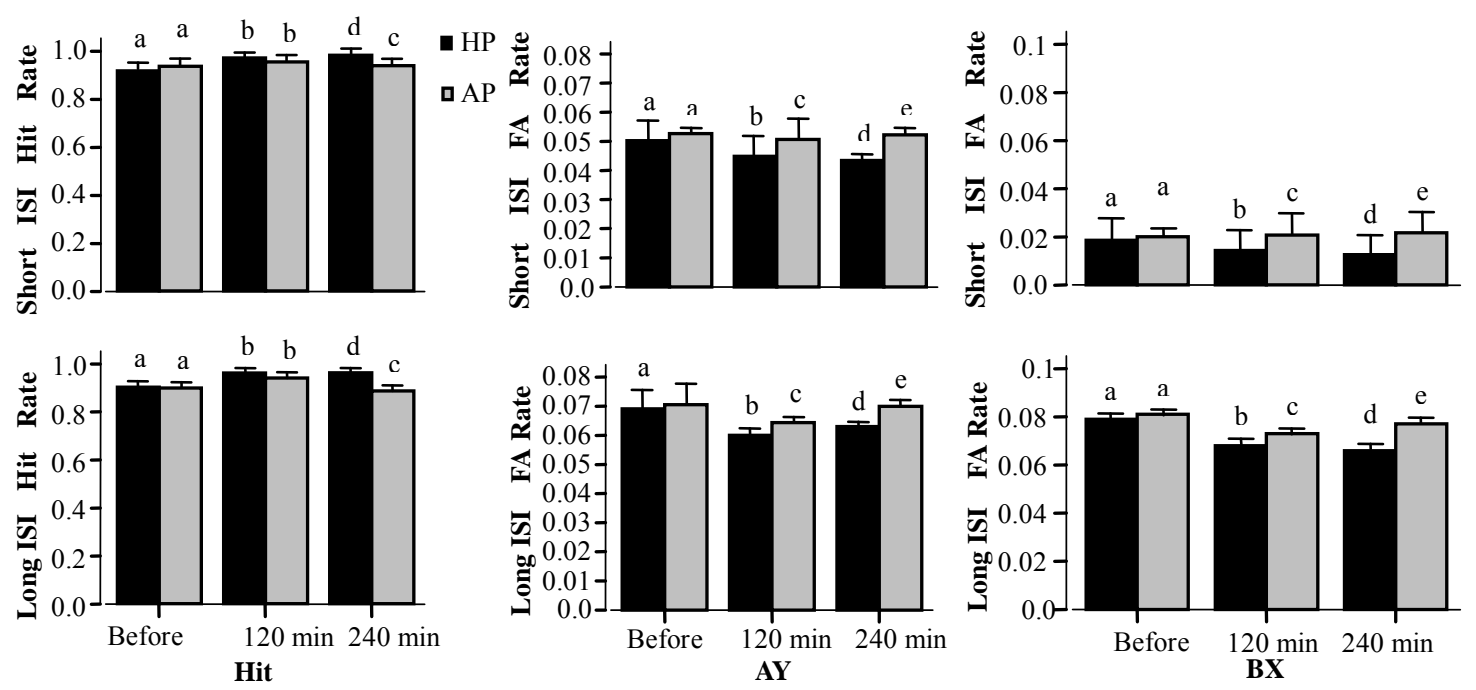

Figure 5. Effects of HP breakfast and AP breakfast on CPT performance. Mean (S.E.M.); $n=13$. Bars without a common superscript differ significantly $(P<0.01)$. 
meal on the evening before the test day. Because the GI of the evening meal was approximately medium, it may not have influenced the glucose tolerance of the subjects at the following morning significantly. Young healthy males are less sensitive to nutritional variables than young females and older people [28] or stress-prone individuals [29]. So our observed effects might be even more pronounced in vulnerable or malnourished population [30].

The Recommended Daily Allowance for protein is 0.8 $\mathrm{g} / \mathrm{kg}$ and the typical Chinese consumes $1.16 \mathrm{~g} / \mathrm{kg}$ or about $15 \%$ of dietary energy as protein [31]. Advocates of high protein diets often recommend that protein intakes meet or exceed $25 \%$ of dietary energy. High protein diets can reduce postprandial glucose rise and maintain stabilization of postprandial insulin are known $[32,33]$. Consistent with the protein content of our test meals, plasma glucose and insulin concentration changed less after the HP meals than after the AP meal. These differences were most pronounced at $0 \mathrm{~min}, 60 \mathrm{~min}$ and $240 \mathrm{~min}$ after test meal ingestion. Because the brain is very sensitive to changes in nutrient supply, small metabolic changes may influence behavior performance [34]. An 'inverted U'-shaped dose-response curve was reported for the effects of plasma glucose [35], and insulin concentration [36] on cognitive functions. It is likely that the ascending or descending part of an 'inverted U' relation represents the acute positive and negative effects of a rise or fall $[37,38]$ in blood glucose concentration on specific cognitive functions. However, constant metabolic conditions [39] might optimize overall cognitive performance [34,27] for a longer time period. The plasma glucose concentration remained nearly constant after the HP meal in present study.

In general, the typical thermic effect of protein is $20 \%$ - $35 \%$ of energy consumed, this number usually falls between $5 \%$ and $15 \%$ for carbohydrate [40]. A main reason for the difference in the thermic effects of food may be due to the fact that the body has no storage capacity for protein and thus it needs to be metabolically processed immediately. The synthesis of protein and the high ATP cost of peptide bond as well as the high cost of urea production and gluconeogenesis are often cited reasons for the higher thermic effect of protein $[41,42]$. Furthermore, concomitant with the thermic response to the test diets was a slight rise in body temperatures. HP feeding was associated with a greater degree of body temperature change versus high carbohydrate (HC) feeding [42] the changes in body temperature were significantly different by diet, HP breakfast was associated with a greater degree of body temperature change versus AP breakfast, and at $120 \mathrm{~min}, 180 \mathrm{~min}$, and $240 \mathrm{~min}$ this change was significant, supporting the contention of
Brundin and Wahren [43] that protein ingestion elicits a pyrogen-like effect.

There is convincing evidence that a higher protein intake increases satiety compared to diets of lower protein content $[33,44,45]$ at least in the short term. We confirmed also that the HP breakfast would increase subjective satiety, but longer experiments would be useful to test whether these beneficial effects on the regulation of appetite can be maintained and have a clinical relevance. However, the mechanisms by which protein may affect satiety remain elusive. Satiety is a complicated interaction of psychological, behavioral and physiological mechanisms. One theory was developed by Mellinkoff [46]. Since amino acid concentrations are correlated with a reduction in appetite, Mellinkoff believed there to be a satiety center in the brain. The satiety center is sensitive to serum amino acid levels and when levels reach a certain point, hunger would cease. Another possible mechanism is a relationship between satiety and dietary induced thermogenesis. In the investigation by Westerterp-Plantenga [10], differences in satiety over a period of 24 hour were significantly correlated with differences in 24 hour dietary induced thermogenesis.

In addition, Blom WA et al [33] believed the HP breakfast reduced the gastric emptying rate and increased satiety, probably through increased secretion of cholecystokinin and glucagon-like peptide 1 . This study indicated the effects of HP breakfast on the mood of healthy males. In assessments performed $0 \mathrm{~min}, 120 \mathrm{~min}$ and $120 \mathrm{~min}$ after breakfast, participants of HP session reported increased positive affect, information uptake and alertness. At the same time, participants of HP session decreased negative affection and arousal. In contrast, participants of AP session reported contrary results. Evidence indicates that macronutrient composition may influence mood by affecting the synthesis of monoamine neurotransmitters [47]. It has been suggested that carbohydrate-rich meals lead to increased fatigue and decreased alertness, whereas meals rich in protein increase alertness and decrease drowsiness [48,28].

The present study indicated HP breakfast can raise the hit rate at long ISI and decline of false alarms of both ISIs than AP breakfast and fasting. Considerable effort has been devoted to studying the relationship between body temperature and human performance [49-51]. It has been reported that cognitive function is improved by increasing body temperature slightly above the normal temperature of $37^{\circ} \mathrm{C}$ and that cognitive function is reduced by decreasing body temperature below normal $[52,53]$. Kleitman [54] originally proposed that the speed of thinking depends on the level of metabolic activity of the cells of the cerebral cortex, and by the raising of the latter through an increase in body temperature we indi- 
rectly speed up the thought process. Kleitman's hypothesis is supported by results from studies $[55,56]$ that higher brain temperatures resulted in faster transmission, whereas lower brain temperature resulted in slower transmission. Moreover, when body temperature was high, alertness was rated higher.

We also hypothesized that protein exerts its mood effects partly through the elevation of postprandial body temperature and glucose concentrations. By bivariate correlation analyses, we found the positive association between body temperature and subjective positive mood, CPT scores at all moments( $0 \mathrm{~min}, 120 \mathrm{~min}$ and $240 \mathrm{~min})$; whereas negative association between body temperature and subjective negative mood. However, the abovementioned association between glucose concentrations and subjective mood, CPT scores only at $240 \mathrm{~min}$ after test breakfast.

\section{CONCLUSIONS}

To conclude, HP breakfast can effectively stabilize postprandial serum glucose concentrations and elevate postprandial temperature of healthy male undergraduate students. Our present findings demonstrate the relationship between HP breakfast and mood, alertness and attention. This study indicated that HP breakfast may enhance human performance probably by increasing the thermic effect of a food and elevating body temperature. This randomized trial demonstrated positive short-term effects of HP breakfast on mood and CPT performance in undergraduate students. The observed differences according to gender and potential mediating effects between mood and performance deserve further investigation.

\section{ACKNOWLEDGEMENTS}

We thank Li-Bo Zhou for providing us with the statistical expertise. We thank Yan-Lin Zhou, Wen-Feng Zhao and Yun-Zhang for their technical assistance. We are also grateful to the research volunteers and a number of assistants of our hospital for their experimental assistance during the study.

Competing interests: The authors declare that they have no competing interests.

Authors' contributions: YZ designed and carried out the experiment of this manuscript and drafted the manuscript and approved the final manuscript; SL and GX participated in the design of the study and revised the manuscript. HS and JW participated the experiment. All authors read and approved the final manuscript. All authors lacked any conflict of interest.

\section{REFERENCES}

[1] Wurtman, R.J. and Wurtman, J.J. (1989) Carbohydrates and depression. Scientific American, 260, 68-75.

doi:10.1038/scientificamerican0189-68

[2] Simopoulos, A.P. (1999) Essential fatty acids in health and chronic disease. The American Journal of Clinical Nutrition, 70, 560S-569S.

[3] Arnold, S.M., Lynn, T.V., Verbrugge, L.A. and Middaugh, J.P. (2005) Human biomonitoring to optimize fish consumption advice: Reducing uncertainty when evaluating benefits and risks. American Journal of Public Health, 95, 393-397.

doi:10.2105/AJPH.2004.042879

[4] Rogers, P.J., Appleton, K.M., Kessler, D., Peters, T.J., Gunnell, D., Hayward, R.C., Heatherley, S.V., Christian, L.M., McNaughton, S.A. and Ness, A.R. (2008) No effect of n-3 long-chain polyunsaturated fatty acid (EPA and DHA) supplementation on depressed mood and cognitive function: a randomized controlled trial. British Journal of Nutrition, 99, 421-431. doi: 10.1017/S0007114507801097

[5] Tappy, L. (1996) Thermic effect of food and sympathetic nervous system activity in humans. Reproduction Nutrition Development, 36, 391-397. doi:10.1051/rnd:19960405

[6] Poppitt, S.D., McCormack, D. and Buffenstein, R. (1998) Short-term effects of macronutrient preloads on appetite and energy intake in lean women. Physiology \& Behavior, 64, 279-285.

doi:10.1016/S0031-9384(98)00061-4

[7] Eisenstein, J., Roberts, S.B., Dallal, G. and Saltzman, E. (2002) High-protein weightloss diets: are they safe and do they work? A review of the experimental and epidemiologic data. Nutrition Reviews, 60, 189-200. doi:10.1301/00296640260184264

[8] Yancy, W.S., Olsen, M.K., Guyton, J.R., Bakst, R.P. and Westman, E.C. (2004) A low-carbohydrate, ketogenic diet versus a low-fat diet to treat obesity and hyperlipidemia: a randomized, controlled trial. Annals of Internal Medicine, 140, 769-777.

[9] Astrup, A. (2005) The satiating power of protein - a key to obesity prevention? The American Journal of Clinical Nutrition, 82, 1-2.

[10] Westerterp-Plantenga, M.S., Rolland, V., Wilson, S.A. and Westerterp, K.R. (1999) Satiety related to $24 \mathrm{~h}$ dietinduced thermogenesis during high protein/carbohydrate vs high fat diets measured in a respiration chamber. European Journal of Clinical Nutrition, 53, 495-502. doi:10.1038/sj.ejen.1600782

[11] Westman, E.C., Yancy, W.S., Edman, J.S., Tomlin, K.F. and Perkins, C.E. (2002) Effect of 6-month adherence to a very low carbohydrate diet program," American Journal of Medicine, 114, 30-36. doi:10.1016/S0002-9343(02)01129-4

[12] Raben, A., Agerholm-Larsen, L., Flint, A., Holst, J.J. and Astrup, A. (2003) Meals with similar energy densities but rich in protein, fat, carbohydrate, or alcohol have different effects on energy expenditure and substrate metabolism but not on appetite and energy intake. The American Journal of Clinical Nutrition, 77, 91-100.

[13] Parker, B., Noakes, M., Luscombe, N. and Clifton, P. (2002) Effect of a high-protein, high-monounsaturated fat weight loss diet on glycemic control and lipid levels in type 2 diabetes. Diabetes Care, 25, 425-430. 
doi:10.2337/diacare.25.3.425

[14] Westerterp-Plantenga, M.S., Lejeune, M.P., Nijs, I., van Ooijen, M. and Kovacs, E.M. (2004) High protein intake sustains weight maintenance after body weight loss in humans. International Journal of Obesity and Related Metabolic Disorders, 28, 57-64. doi:10.1038/sj.ijo.0802461

[15] Lejeune, M.P., Kovacs, E.M. and Westerterp-Plantenga, M.S. (2005) Additional protein intake limits weight regain after weight loss in humans. British Journal of $\mathrm{Nu}$ trition, 93, 281-289. doi:10.1079/BJN20041305

[16] Layman, D.K., Boileau, R.A., Erickson, D.J, Painter, J.E., Shiue, H., Sather, C. and Christou, D.D. (2003) A reduced ratio of dietary carbohydrate to protein improves body composition and blood lipidprofiles during weight loss in adult women. Journal of Nutrition, 133, 411-417.

[17] Farnsworth, E., Luscombe, N.D., Noakes, M., Wittert, G., Argyiou, E. and Clifton, P.M. (2003) Effect of a highprotein, energy-restricted diet on body composition, glycemic control, and lipid concentrations in overweight and obese hyperinsulinemic men and women. The American Journal of Clinical Nutrition, 78, 31-39.

[18] Widenhorn-Müller, K., Hille, K., Klenk, J. and Weiland, U. (2008) Influence of having breakfast on cognitive performance and mood in 13- to 20-year-old high school students: Results of a crossover trial. Pediatric, 122, 279-284. doi:10.1542/peds.2007-0944

[19] Chitra, U. and Reddy, C.R. (2006) The role of breakfast in nutrient intake of urban schoolchildren. Public Health Nutrition, 10, 55-58.

[20] Gajre, N.S., Fernandez, S., Balakrishna, N. and Vazir, S. (2008) Breakfast eating habit and its influence on attention-concentration, immediate memory and school achievement. Indian Pediatrics, 45, 824-828.

[21] Kaplan, R.J., Greenwood, C.E., Winocur, G. and Wolever, T.M. (2001) Dietary protein, carbohydrate, and fat enhance memory performance in the healthy elderly. The American Journal of Clinical Nutrition, 74, 687-693.

[22] Haber, G.B., Heaton, K.W., Murphy, D. and Burroughs, L.F. (1977) Depletion and disruption of dietary fibre. Effects on satiety, plasma-glucose, and serum-insulin. The Lancet, 2, 679-682. doi:10.1016/S0140-6736(77)90494-9

[23] Davis, L.M., Coleman, C., Kiel, J., Rampolla, J., Hutchisen, T., Ford, L., Andersen, W.S. and Hanlon-Mitola, A. (2010) Efficacy of a meal replacement diet plan compared to a food-based diet plan after a period of weight loss and weight maintenance: a randomized controlled trial. Nutrition Journal, 9, 1-10. doi:10.1186/1475-2891-9-11

[24] Hlebowicz, J., Wickenberg, J., Fahlström, R., Björgell, O., Almér, L.O. and Darwiche, G. (2007) Effect of commercial breakfast fibre cereals compared with corn flakes on postprandial blood glucose, gastric emptying and satiety in healthy subjects: a randomized blinded crossover trial Joanna. Nutrition Journal, 6, 1-7. doi:10.1186/1475-2891-6-22

[25] Feist, A. and Stephan, E. (2004) Verfahren zur Erfassung des Gefü hlszustandes (Mood Assessment Scale; in German). Germany University of Cologne.
[26] Umbricht, D., Vollenweider, F.X., Schmid, L., Grübel, C., Skrabo, A., Huber, T. and Koller, R. (2003) Effects of the 5-HT2A Agonist Psilocybin on Mismatch Negativity Generation and AX-Continuous Performance Task: Implications for the Neuropharmacology of Cognitive Deficits in Schizophrenia. Neuropsychopharmacology, 28, 170-181. doi:10.1038/sj.npp.1300005

[27] Fischer, K., Colombani, P.C., Langhans, W. and Wenk, C. (2001) Cognitive performance and its relationship with postprandial metabolic changes after ingestion of different macronutrients in the morning. British Journal of Nutrition, 85, 393-405. doi:10.1079/BJN2000269

[28] Spring, B., Maller, O., Wurtman, J., Digman, L. and Cozolino, L. (1982-1983) Effects of protein and carbohydrate meals on mood and performance: interactions with sex and age. Journal of Psychiatric Research, 17, 155167. doi:10.1016/0022-3956(82)90017-6

[29] Markus, C.R., Panhuysen, G., Tuiten, A., Koppeschaar, H., Fekkes, D. and Peters, M.L. (1998) Does carbohydrate-rich, protein-poor food prevent a deterioration of mood and cognitive performance of stress-prone subjects when subjected to a stressful task? Appetite, 31, 49-65. doi:10.1006/appe.1997.0155

[30] Pollitt, E., Cueto, S. and Jacoby, E.R. (1998) Fasting and cognition in well- and undernourished schoolchildren: a review of three experimental studies. The American Journal of Clinical Nutrition, 67, 779S-784S.

[31] Chinese Nutrition Society. (2000) China Dietary Reference Intakes (DRIs). China Light Industry Publishing Company, Beijing.

[32] Nuttall, F.Q., Mooradian, A.D., Gannon, M.C., Billington, C. and Krezowski, P. (1984) Effect of protein ingestion on the glucose and insulin response to a standardized oral glucose load. Diabetes Care, 7, 465-470. doi:10.2337/diacare.7.5.465

[33] Blom, W.A., Lluch, A., Stafleu, A., Vinoy, S., Holst, J.J., Schaafsma, G. and Hendriks, H.F. (2006) Effect of a high-protein breakfast on the postprandial ghrelin response. The American Journal of Clinical Nutrition, 83, 211-220.

[34] De-Feo, P., Gallai, V., Mazzotta, G., Crispino, G., Torlone, E., Perriello, G., Ventura, M.M., Santeusanio, F., Brunetti, P. and Bolli, G.B. (1988) Modest decrements in plasma glucose concentration cause early impairment in cognitive function and later activation of glucose counterregulation in the absence of hypoglycemic symptoms in normal man. The Journal of Clinical Investigation, 82, 436444. doi:10.1172/JCI113616

[35] Parsons, M.W. Gold, P.E. (1992) Glucose enhancement of memory in elderly humans: an inverted-U dose-response curve. Neurobiology of Aging, 13, 401-404. doi:10.1016/0197-4580(92)90114-D

[36] Cahill, L. and McGaugh, J.L. (1996) Modulation of memory storage. Current Opinion in Neurobiology, 6, 237-242. doi: 10.1016/50959-4388(96)80078-X

[37] Owens, D.S. and Benton, D. (1994) The impact of raising blood glucose on reaction times. Neuropsychobiology, 30, 
106-113.

doi:10.1159/000119146

[38] Owens, D.S., Parker, P.Y. and Benton, D. (1997) Blood glucose and subjective energy following cognitive demand. Physiology \& Behavior, 62, 471-478. doi:10.1016/S0031-9384(97)00156-X

[39] Santucci, A.C., Schroeder, H. and Riccio, D.C. (1990) Homeostatic disruption and memory: effect of insulin administration in rats. Behavioral and Neural Biology, 53, 321-333. doi:10.1016/0163-1047(90)90184-8

[40] Westerterp, K.R., Wilson, S.A. and Rolland, V. (1999) Diet induced thermogenesis measured over $24 \mathrm{~h}$ in a respiration chamber: effect of diet composition. International Journal of Obesity and Related Metabolic Disorders, 23, 287-292. doi: $10.1038 /$ sj.ijo. 0800810

[41] Mikkelsen, P.B., Toubro, S. and Astrup, A. (2000) Effect of fat reduced diets on $24 \mathrm{~h}$ energy expenditure: Comparisons between animal protein, vegetable protein and carbohydrate. The American Journal of Clinical Nutrition, 72, 1135-1141.

[42] Johnston, C.S., Day, CS. and Swan, P.D. (2002) Postprandial thermogenesis is increased $100 \%$ on a highprotein, low-fat diet versus a high-carbohydrate, low-fat diet in healthy, young women. The American Journal of Clinical Nutrition, 21, 55-61.

[43] Brundin, T. and Wahren, J. (1994) Influence of protein ingestion on human splanchnic and whole-body oxygen consumption, blood flow, and blood temperature. Metabolism, 43, 626-632. doi:10.1016/0026-0495(94)90206-2

[44] Veldhorst, M.A., Nieuwenhuizen, A.G., HochstenbachWaelen, A., Westerterp, K.R., Engelen, M.P., Brummer, R.J., Deutz, N.E., Westerterp-Plantenga, M.S. (2009) Comparison of the effects of a high- and normal-casein breakfast on satiety, 'satiety' hormones, plasma amino acids and subsequent energy intake. British Journal of Nutrition, 101, 295-303. doi:10.1017/S0007114508003061

[45] Leidy, H.J., Bossingham, M.J., Mattes, R.D. and Campbell, W.W. (2009) Increased dietary protein consumed at breakfast leads to an initial and sustained feeling of fullness during energy restriction compared to other meal times. British Journal of Nutrition, 101, 798-803. doi: $10.1017 / \mathrm{S} 0007114508051532$
[46] Mellinkoff, S.M., Frankland, M., Boyle, D. and Greipel, M. (1956) Relationship between serum amino acid concentration and fluctuations in appetite. Journal of Applied Physiology, 8, 535-588.

[47] Gibson, L.E. and Green, M.W. (2002) Nutritional influences on cognitive function: mechanisms of susceptibility. Nutrition Research Reviews, 15, 169-206. doi:10.1079/NRR200131

[48] Lloyd, H.M., Rogers, P.J., Hedderley, D.I. and Walker, A.F. (1996) Acute effects on mood and cognitive performance of breakfasts differing in fat and carbohydrate content. Appetite, 27, 151-164. doi:10.1006/appe.1996.0042

[49] Allan, J.R., Gibson, T.M. and Green, R.G. (1979) Effect of induced cyclic changes of deep body temperature on task performances. Aviation, Space, and Environmental Medicine, 50, 585-589.

[50] Coleshaw, S.R., Van Someren, R.N., Wolff, A.H., Davis, H.M. and Keatinge, W.R. (1983) Impaired memory registration and speed of reasoning caused by low body temperature. Journal of Applied Physiology, 55, 27-31.

[51] Wright, K.P., Hull, J.T. and Czeisler, C.A. (2002) Relationship between alertness, performance, and body temperature in humans. American Journal of Physiology -Regulatory, Integrative and Comparative Physiology, 283, 1370-1377.

[52] Giesbrecht, G.G. (2000) Cold stress, near drowning and accidental hypothermia: A review. Aviation, Space, and Environmental Medicine, 71, 733-752.

[53] Giesbrecht, G.G., Arnett, J.L., Vela, E. and Bristow, G.K. (1993) Effect of task complexity on mental performance during immersion hypothermia. Aviation, Space, and Environmental Medicine, 64, 206-211.

[54] Kleitman, N. and Jackson, D.P. (1950) Body temperature and performance under different routines. Journal of Applied Physiology, 3, 309-328.

[55] Masino, S.A. and Dunwiddie, T.V. (2000) A transient increase in temperature induces persistent potentiation of synaptic transmission in rat hippocampal slices. Neuroscience, 101, 907-912. doi:10.1016/S0306-4522(00)00431-0

[56] Volgushev, M., Vidyasagar, T.R., Chistiakova, M. and Eysel, U.T. (2000) Synaptic transmission in the neocortex during reversible cooling. Neuroscience, 98, 9-22. doi:10.1016/S0306-4522(00)00109-3

\section{ABBREVIATIONS}

HP: high protein;

AP: adequate protein;

CPT: continuous performance test;

BMI: body mass index;
HC: high carbohydrate;

GI: glycemic index;

VAS: visual analogue scales 